\title{
Don't Fake It, Make It! Best Practices for Attending Virtual Events ${ }^{1}$
}

\author{
Jarred A. Shellhouse and Lauri M. Baker ${ }^{2}$
}

\section{Introduction}

Continuing the Don't Fake It, Make It! series to make the most out of virtual conferences and meetings, this fact sheet provides tips specific to attendees. Up to this point, the series has focused largely on the process a host should go through before launching a virtual event. This publication shifts the focus from virtual host to virtual participant to allow attendees of the virtual event to get the most out of the experience. While the spotlight is on attending virtual conferences in particular, the suggestions below can translate to other virtual meeting spaces.

\section{Why attend virtually?}

Hosting conferences or meetings in virtual environments fosters a number of benefits for both the conference host and participants, such as decreased lodging, catering, and participants' travel costs (Shirmohammadi et al., 2012), and less on-site staff fees for hosts (Arnal et al., 2020). Connecting to a virtual conference can also improve accessibility for many participants, with existing translating and closed-captioning software making it easier for participants who do not speak the conference's native language. Additionally, conference presenters often share their screen to display visual aids, which brings supplemental content on the screen of the participant, closer and possibly clearer than they would see it in person (Arnal et al., 2020). In 2020, virtual events were up $1,000 \%$ due to the COVID-19 pandemic (Koetsier, 2020), so almost everyone attended a virtual event of some sort. However, virtual participation can pose some unanticipated challenges for individuals participating for the first time in a virtual experience.

\section{Best Practices}

Adopting the role of virtual participant is not easy for everyone, because the online component can sometimes feel isolating and less engaging. The following suggestions will help smooth the transition from an in-person attendee to a virtual participant. Table 1 gives an overview of the following practices and when you should consider them. The table components are explained below in detail.

\section{Prior to the Virtual Conference Clear your schedule for the conference duration}

As an in-person participant, meetings and other commitments would have been deleted from your calendar prior to traveling. Why treat a virtual ticket any differently? Ensuring schedules are free of "normal" workday distractions will help you get the most out of a virtual conference or meeting. Otherwise, participants may feel the need to log out and take care of the distraction, which poses a risk of missing crucial pieces of knowledge needed for the rest of the conference.

1. This document is AEC710, one of a series of the Department of Agricultural Education and Communication, UF/IFAS Extension. Original publication date October 2020. Visit the EDIS website at https://edis.ifas.ufl.edu for the currently supported version of this publication.

2. Jarred A. Shellhouse, marketing specialist, and Lauri M. Baker, associate professor, Department of Agricultural Education and Communication, UF/IFAS Extension, Gainesville, FL 32611.

The Institute of Food and Agricultural Sciences (IFAS) is an Equal Opportunity Institution authorized to provide research, educational information and other services

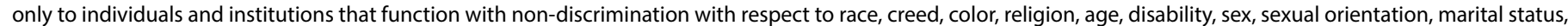

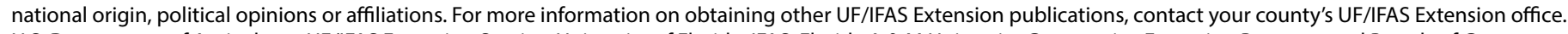
U.S. Department of Agriculture, UF/IFAS Extension Service, University of Florida, IFAS, Florida A \& M University Cooperative Extension Program, and Boards of County Commissioners Cooperating. Nick T. Place, dean for UF/IFAS Extension. 
- Reschedule any meetings and complete the work for any project deadlines that occur during the conference or meeting. That way, these do not stand as distractions while you are trying to be virtually present in the experience.

- Set an "out of office" message on email accounts, so no temptation or guilt exists for not checking and responding to emails right away.

- If you are in a shared workspace, considering putting a physical sign on your door or entry to your workspace. This signage should include the name of the meeting or conference you're attending and when you will be available again (during a conference break, or perhaps not until the entire function is over). You can also indicate how you would prefer they reach you during this time, such as via text, instant message, or email.

\section{Prepare by researching content and expectations}

It is likely the hosts will communicate with all virtual participants in the days or weeks leading up to the event. You receive that communication because the host thought it was important for you to have. Therefore, your effort toward consuming that information can help set you up to be an actively engaged virtual participant.

- Read the messages the host sends and watch any included videos. Because social time in between sessions will not be as accessible, asking questions may be challenging. The correspondence received prior to the event may contain vital information about downloading specific software or understanding expectations about using a webcam or microphone.

- Carefully read the agenda beforehand and pay special attention to the time zone. The virtual hosts will likely publish the schedule according to their local time, which may need to be converted to your local time in a different zone. Reading through the schedule prior to attending will also help create awareness of content that is of particular interest to you.

- Become familiar with the videoconferencing software being used. If the virtual hosts are using videoconferencing software unfamiliar to you, download the software prior to attending, watch tutorial videos, and learn more about the features of the software before taking on the role of a virtual participant. Engaging with the conference content will be difficult if most of your time is spent learning how to work the videoconferencing software.
- Give notice to your supervisor and co-workers that you will be attending a virtual conference and will be unavailable during the conference times for other meetings or unplanned check-ins.

\section{Download/test software and equipment}

It is always possible that something unexpected happens at the last minute that will require you to troubleshoot your internet access or update needed software, but these hiccups could also happen in person. (Think about a conference with an unexpected fire alarm, causing the building's occupants to evacuate in the middle of a session.) While the unexpected is also unplanned, testing out equipment prior to the conference start time can help get you ready and reduce any technological anxiety you may have.

- On the first day of the virtual conference or meeting, log in early. Test out the internet connection, the webcam lighting and quality, microphones, and speakers to ensure all hardware is working correctly, setting everything up for a pleasant experience.

- Create a backup plan. Unexpected events happen, like a neighbor mowing the lawn, internet dropping out, or a fire drill in your building. Have another location in mind that could be used if the need arises, so you can get the experience you paid for even with a minor setback.

\section{Schedule/plan for meals}

Hybrid meetings and conferences with both virtual and in-person participants will likely have food catered, or at least a plan for meals. However, virtual participants will not have access to that food, and it is likely you will still want sustenance.

- Pay attention to the schedule and have a plan in place for food to be delivered at a certain time, or plan to eat something easily accessible. The time that the in-person participants have to eat the catered meal is the time virtual participants have to both make food and eat before the next session begins. If there is a keynote speaker during a lunch or meal function, it will be even more important that you plan your food ahead of time.

- Having snacks available and accessible for smaller breaks can help curb hunger while staying present in the virtual meeting space.

\section{Consider participating with a buddy}

Depending on the host's experience with hosting virtual conferences, some items may not translate to virtual spaces as easily as anticipated. In these situations, having a buddy 
to check in with can help ensure you are understanding the content or tasks at hand as clearly as the host intends.

- If another person is interested in the same meeting or conference, encourage the person to also participate virtually. Even if the person is not located in the same physical space, having another person work through the same virtual conference can be helpful to ask informal questions, work together on group work, or take notes if one person needs to step out.

- Consider setting up a time after the conference to debrief what you learned and plan together about how each of you will implement what you will learn throughout the conference in your work.

\section{During the Virtual Conference}

\section{Immerse in the experience}

The host has invested significant resources to conduct this conference and bring it to you in a virtual space. You are also investing your time and resources into being a participant, so immerse yourself in the conference in its entirety.

- Prepare to spend the entire conference time fully engaged with the webcam on. The more virtual participants actively engage with the content, the more they get out of the experience.

- Take notes, work through the conference workbook if one is available, and ask questions when something is unclear. Virtual participants are just as important as in-person participants, so ensure you get as much value out of the experience as someone who may be physically present.

\section{Engage with other participants}

Part of the conference experience is meeting other likeminded individuals. A virtual experience is no different.

- If the conference has networking opportunities built in, take advantage of these experiences. It is tempting to schedule over these experiences or prioritize other in-person work, but if you don't take time to participate in these functions, you are missing out on future collaborations with colleagues and learning from what others are doing in similar positions.

- If the conference doesn't have built-in networking opportunities, or if you want to take them to the next level, connect with your fellow participants in other ways. If there is a conference chat feature available, start a conversation with another participant about one of the sessions. If you notice someone has a similar position as you at another institution or business, reach out to the person via LinkedIn or email to start a conversation about your shared conference experience. These opportunities can lead to future collaborations and will make you feel like your virtual experience lives up to an in-person experience.

\section{Following the Virtual Conference Consolidate your notes and form an action plan}

As a virtual participant, it can be more difficult to connect with others to talk through ideas or process what you learned, but reflection is still an important step in the process.

- Review your notes and consolidate them into actionable steps.

- Use the action steps to formulate a plan going forward. If it is an annual conference, set goals and/or calendar reminders to accomplish some of your action steps before returning to the conference next year, either in-person or virtually.

\section{Follow up with other participants about possible collaborations}

As an in-person participant, you have an opportunity to swap business cards and follow up with each other later. When participating virtually, you might have access to participants' email addresses or contact information. Use it!

- Reach out to other participants after the experience is over. You can start a small group to work on an idea or experience from the conference or simply schedule an online coffee or happy hour experience to continue a professional relationship post conference.

- Should you have questions, remember that other participants and presenters may still be willing to help out, especially if they have given contact information. Use the conference as a professional relationship-building tool to expand your network and follow through with collaboration ideas.

- If the conference utilized social media or a specific hashtag, peruse the posts to see if there is any other information you can gain or connections you can make before your conference experience concludes. 


\section{Conclusion}

A virtual conference is about what you make of the experience, much like an in-person conference. While the quality of virtual conferences may vary depending on the size, content area, and host's previous virtual experience, you have the power as an attendee to make the experience the best it can be by preparing and researching for the conference, making time to fully participate and engage, and connecting with other attendees and presenters. To achieve a high return on investment, put in some effort researching the conference beforehand, immerse yourself in the experience for the full duration, and follow up with other conference participants afterward. Being an active participant on all fronts will help you have a pleasant and successful virtual attendee experience.

\section{References}

Arnal, A., Epifanio, I., Gregori, P., \& Martìnez, V. (2020). Ten simple rules for organizing a non-real-time web conference. PLoS Computational Biology, 16(3), 1-13. https://doi. org/10.1371/journal.pcbi.1007667

Koetsier, J. (2020). Virtual events up 1000\% since COVID19 , with 52,000 on just one platform. Forbes Online. https://www.forbes.com/sites/johnkoetsier/2020/05/27/ virtual-events-up-1000-with-52000-on-just-one-platform/

Shirmohammadi, S., Hu, S. Y., Ooi, W. T., Shiele, G., \& Wacker, A. (2012, October 8-9). Mixing virtual and physical participation: The future of conference attendance? [Paper presentation]. Haptic Audio Visual Environments and Games, Munich, Germany.

\section{Appendix}

1. Don't Fake It, Make It! Thriving in Virtual Conferences and Meetings

2. Applying Learning Theory to Virtual Conference Spaces

3. Am I Ready? Competencies and Skill Sets Needed for Virtual Conference Hosts

4. Technology and Tools for Virtual Hosts

5. Let's Do This Right: Best Practices for Hosting Virtual Conferences

6. Host with the Most: Best Practices for Hosting Virtual Meetings

7. Best Practices for Hosting Virtual Webinars

8. Best Practices for Hosting Virtual Events and Fairs

9. Best Practices for Attending Virtual Events

Table 1. Best practices for virtual attendees in relation to conference timing.

\begin{tabular}{|l|l|l|}
\hline \multicolumn{1}{|c|}{ Prior to the Virtual Conference } & \multicolumn{1}{|c|}{ During the Virtual Conference } \\
\hline $\begin{array}{l}\text { Clear your schedule for the conference } \\
\text { duration. }\end{array}$ & $\begin{array}{l}\text { Check to make sure you've set an out-of-office } \\
\text { email reply. }\end{array}$ & $\begin{array}{l}\text { Consolidate your notes and form an action } \\
\text { plan. }\end{array}$ \\
\hline $\begin{array}{l}\text { Prepare by researching content and } \\
\text { expectations. }\end{array}$ & Add a “Do Not Disturb" sign on your office door. & $\begin{array}{l}\text { Follow up with other participants about } \\
\text { possible collaborations. }\end{array}$ \\
\hline Download/test software and equipment. & $\begin{array}{l}\text { Immerse in the experience; take notes; ask } \\
\text { questions. }\end{array}$ & \\
\hline Schedule/plan for meals. & Engage with other participants. & \\
\hline Consider participating with a buddy. & & \\
\hline
\end{tabular}

